\section{A cada instante, avaliamos}

\section{e somos avaliados.}

O ser humano se avalia e é avaliado diariamente. Ao final de cada dia, imperceptivelmente, cada um de nós está com bom ou mau humor. Com certeza, essa sensação tem algo a ver com o balanço das avaliações que fizemos e que fizeram de nós mesmos:

- Terei dormido bem?

- Chegarei a tempo ao trabalho?

- O chefe e/ou os chefiados estarão receptivos?

- Estou desempenhando bem meu ofício?

- Esta é a roupa que devo usar na festa?

- Estou elegante?

- Saí-me bem na reunião?

Quantas outras perguntas nos fazemos e quantas fazemos em relação aos outros! Somos seres avaliativos. O tempo todo. No extremo, podemos chegar à maledicência...

Apesar dessa intensa convivência, temos medo da avaliação. Tememos tanto avaliar quanto sermos avaliados.

Se isso acontece informalmente no dia-a-dia, o que não acontece na atividade de avaliação em educação? Alunos, professores, gestores, administradores, todos são questionados quando os resultados das avaliações escolares ficam abaixo dos desejados. E então...

Certamente, refletir sobre esse fenômeno pode diminuir nossa ansiedade tanto ao avaliarmos quanto ao sermos avaliados. Mas a questão não é apenas diminuir a tensão. A questão é: o que fazer com os resultados de uma avaliação, seja ela pessoal, seja profissional?

Esta edição do CADERNOS CENPEC oferece um semnúmero de argumentos para que enfrentemos profissionalmente o tema da avaliação em educação. Nesta seção, procuramos complementar essa oferta, apresentando alguns filmes, livros, artigos e sítios. Nossa intenção é que, com mais elementos para reflexão, certamente ampliaremos nossa consciência e poderemos desenvolver ações mais conseqüentes.

* Fernando Rıos é jornalista, publicitário, cientista social e consultor em comunicação organizacional integrada.

ISA MARIA F. RoSA GUARÁ é pedagoga, doutora e mestre em Serviço Social (PUC-SP) e pós-graduada em Psicopedagogia. É consultora em programas e projetos sociais.

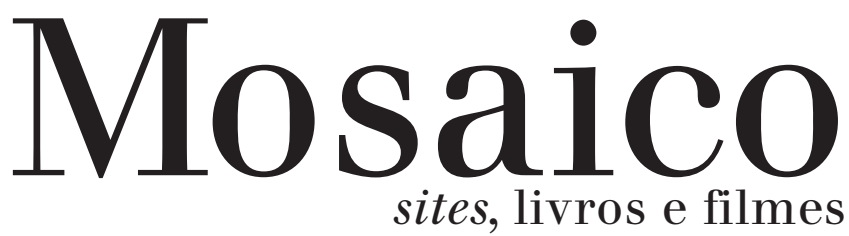

FERNANDO RIOS

ISA MARIA F. ROSA GUARÁ*

Filmes

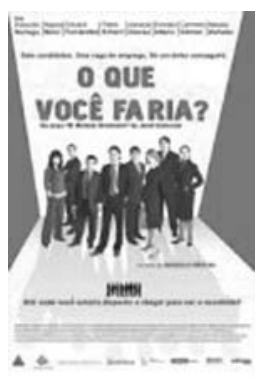

O que você faria

DIRETOR: MARCELO PIÑEYRO.

ATORES: EDUARDO NORIEGA, NAJWA NIMRI, EDUARD FERNÁNDEZ, PABLO ECHARRI, ERNESTO ALTERIO, CARMELO GÓMEZ, ADRIANA OZORES, NATALIA VERBEKE.

DRAMA, ESPANHA-ARGENTINA-ITÁLIA, 2005, 115 MINUTOS. Uma situação de avaliação, no mais alto nível, de uma competitividade que pretende ser cordial: sete executivos se candidatam a um emprego e se submetem a um processo de seleção no mesmo dia em que Madri é movimentada por marchas de protesto contra a globalização e a política monetária do FMI, que realiza sua reunião no mesmo prédio. 0 grupo é deixado a sós em uma sala e são promovidos vários testes por computador que pretendem avaliar a interação entre eles. De início, todos acreditam ter controle sobre seu comportamento e emoções, mas os jogos os levam a situações-limite que, aliadas ao fato de saberem estar sendo observados, colocam-nos em um nível de tensão insuportável. As alianças, paranóias, medos e misérias não tardam a aparecer.

Em um clima claustrofóbico, de máxima desconfiança e absoluta falta de escrúpulos, acontecem acordos, disputas, revelam-se segredos, vêm à tona conflitos passados. Aos poucos, emerge uma inconseqüente e fria luta pela sobrevivência, muito comum em nossa economia capitalista globalizada. 
Segundo o crítico Luiz Carlos Merten, "a força do filme vem das relações. A personagem da mulher fornece a chave e é magnífica. 0 mundo globalizado ficou pior, mas o cinema do argentino Marcelo Piñeyro continua ótimo".

Ganhou dois prêmios no Goya, da Academia das Artes e Ciências Cinematográficas da Espanha, nas categorias de Melhor Ator Coadjuvante (Carmelo Gómez) e Melhor Roteiro Adaptado (Mateo Gil e Marcelo Piñeyro). Foi, ainda, indicado nas categorias de Melhor Ator (Eduard Fernández), Melhor Revelação Masculina (Pablo Echarri) e Melhor Edição (Ivan Aledo).

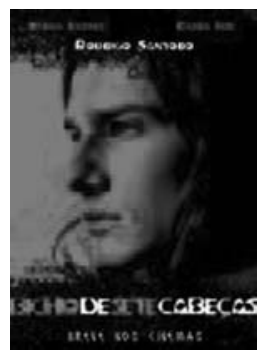

\section{Bicho de sete cabeças}

DIRETORA: LAÍS BODANSKY.

ATORES: RODRIGO SANTORO, OTHON BASTOS, CÁSSIA KISS E CACO CIOCLER.

DRAMA, BRASIL, 2000, 80 MINUTOS.

Quem pode ter a verdade numa conflituosa relação pai e filho? Quem estrutura a família? Como um jovem pode reagir a fatos que acontecem no cotidiano, compreendê-los, avaliálos, fazer prevalecer sua individualidade e permanecer ileso?

Este filme de Laís Bodansky é um convite à reflexão. Tudo é questionado: a família, a paternidade, a maternidade, a juventude, a questão das drogas, o tratamento hospitalar de deficientes mentais, a sociedade contemporânea, a urbanidade...

E neste vórtice de inconseqüências, cada personagem se apresenta diante e em relação ao personagem central, o adolescente Neco, interpretado por Rodrigo Santoro, que parece caminhar inexoravelmente para uma tragédia.

Não se diga que o filme retrata uma típica família de classe média periférica brasileira. Mas essas famílias costumam apresentar muitas dessas situações. É um trabalho supercuidadoso, com ótima direção de atores e belos movimentos de câmera.

O crítico Thiago P. Ribeiro faz uma síntese elucidativa:

Temos o prazer em ver Rodrigo Santoro mostrar por que está onde está. Internados em seus pensamentos difusos e fora do normal, os atores conseguem retratar com perfeição o mundo criado pelos roteiristas, diretores e diretores de arte.

Afinados com a falta de realidade comum entre os internos de qualquer manicômio, os atores parecem se fechar em mundos próprios, recôncavos e circundados por delicados movimentos e olhares sem expressão definida. Caminham pelo pátio entediados, sem esperança, sujos, renegados. Os melhores momentos são aqueles em que a prisão, imposta pela sociedade aos rotulados 'fora do padrão', revela personagens criados com carinho pelos cineastas e atores. São nas mínimas expressões entre alento e perdição que encontramos o tom do filme.

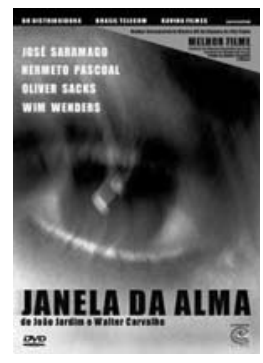

\section{Janela da alma}

DIRETORES: JOÃO JARDIM E WALTER CARVALHO.

ENTREVISTADOS: AGNES VARDA, ANTÔNIO CÍCERO, ARNALDO GODOY, CARMELLA GROSS, EUGEN BAVCAR, HANNA SHYGULLA, HERMETO PASCOAL, JOÃO UBALDO RIBEIRO, JOSÉ SARAMAGO, MADALENA GODOY, MANOEL DE BARROS, MARIETA SEVERO, MARJUT RIMMINEN, OLIVER SACKS, PAULO CEZAR LOPES, WALTER LIMA JR., WIM WENDERS. DOCUMENTÁRIO, BRASIL, 2001, 73 MINUTOS.

"O olho abraça a beleza do mundo inteiro. É janela do corpo, por onde a alma especula e frui a beleza do mundo. 0 que há de admirável no olho é que através dele - de um espaço tão reduzido - seja possível a absorção das imagens do universo. De sorte que esse órgão - um entre tantos - é a janela da alma, o espelho do mundo." Esse texto, atribuído a Leonardo da Vinci (além de tudo, ele sabia escrever bem) serviu de epígrafe e inspiração para este maravilhoso filme que fala sobre ver, olhar, enxergar, discernir, vislumbrar, descortinar... a vida e seus pertences, visíveis pelo olho e pela alma. 


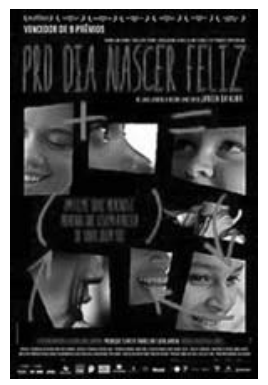

Utilizando um grupo seleto de entrevistados, de míopes e cegos - entre eles, o escritor e Prêmio Nobel José Saramago, o músico Hermeto Paschoal, o cineasta Wim Wenders, o fotógrafo cego franco-esloveno Evgen Bavcar, o neurologista Oliver Sacks, a atriz Marieta Severo, o vereador cego de Belo Horizonte, Arnaldo Godoy - o filme nos propõe uma reflexão que remete para a maneira de cada um estar no mundo, percebê-lo e interpretá-lo.

Todos trazem revelações surpreendentes: do funcionamento fisiológico do olho, o significado de ver ou não a poluição visual que domina o planeta até a importância das emoções como elemento transformador da realidade. Cada um deles, a partir de sua deficiência, maior ou menor, articula uma nova eficiência. Esta é uma das grandes lições do trabalho de João Jardim e Walter Carvalho. Uma lição que pode enriquecer o dia-a-dia de qualquer pessoa, sobretudo de professores e alunos.

Janela da Alma ganhou o Grande Prêmio Cinema Brasil de Melhor Documentário e recebeu outras seis indicações: Melhor Diretor, Melhor Roteiro Original, Melhor Trilha Sonora, Melhor Montagem, Melhor Fotografia e Melhor Som; o prêmio de Melhor Documentário, no Festival do Rio 2001; os prêmios de Melhor Documentário - Júri Oficial e Melhor Documentário - Júri Popular, na Mostra de Cinema de São Paulo.

Depois que abrimos com cuidado a "Janela da Alma" e lançamos nosso olhar sobre a paisagem que ela propõe, notamos quão importante é sentir a realidade e perceber que é possivel transformá-la para melhor.

\section{Pro dia nascer feliz}

DIRETOR: JOÃO JARDIM.

DOCUMENTÁRIO, BRASIL, 2006, 88 MINUTOS.

Provavelmente, o melhor documentário já feito no Brasil comparando escolas públicas e particulares, por meio de depoimentos de adolescentes de classes baixa, média e alta, mesmo considerando que uma entrevistada tenha subido ao palco do Cine Sesc São Paulo, na estréia, para protestar contra os trechos escolhidos de sua entrevista. Ainda assim, os depoimentos de adolescentes de áreas urbanas e rurais, dos estados de São Paulo, Rio de Janeiro e Pernambuco revelam angústias, esperanças e desesperanças, incertezas e conflitos vividos por eles.

Não se podem generalizar as situações apresentadas em Pro Dia Nascer Feliz. Contudo, no fim do filme sobra um grande desalento em relação ao ensino público, no qual o adolescente brasileiro enfrenta preconceito, precariedade e violência. Ao menos é traçado um retrato realista das adversidades enfrentadas pelos adolescentes nas escolas brasileiras e a reprodução de um sistema social injusto, no qual apenas os ricos têm acesso às melhores escolas, aos melhores empregos e, conseqüentemente, às melhores condições de vida. Uma denúncia que merece apuração e medidas para transformá-la.

Em um bate-papo no site UOL, o diretor João Jardim comentou seu trabalho:

A idéia do documentário nasceu quando eu estava fazendo uma pesquisa sobre gravidez precoce. Comecei a perceber que os adolescentes reclamavam muito da escola. Esse antagonismo entre 0 adolescente e a escola foi o ponto de partida para fazer o filme.

(Este filme é) ... um diário de observação. Acompanhei durante um tempo o que os adolescentes viviam. É um filme de pessoas contando histórias, misturadas com imagens de momentos da vida deles. Basicamente todas as histórias me chocaram. A que mais me choca é a história de uma menina que matou uma colega. Ela já estava presa, eu fui atrás um tempo depois e colhi o depoimento dela. A variação do tom é muito grande, esse momento é muito imprevisível. É uma mistura de tédio com emoção. 


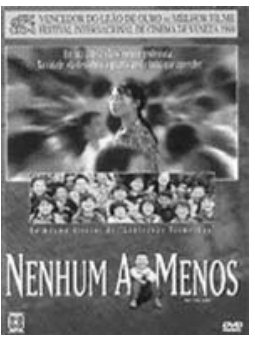

Acho que é muito essa questão de o mundo ter mudado muito e a educação ainda ser a mesma. A família é o que tem de mais importante, às vezes no momento que o filho precisa de apoio, os pais são muito rígidos e vice-e-versa. Falta uma discussão melhor dentro da escola sobre o que está acontecendo com o jovem. Ninguém precisa dizer aos pais como fazer, mas vale explicar melhor. (...) os professores estão na mesma realidade que os alunos. É um pouco sem saída. O professor não sabe lidar muito bem com o jovem, ele está aí sem os recursos necessários. Os diretores, mais ainda.

A situação, que não parece ser nova para quem está no magistério, também não vem sendo alvo de estudo pelas Universidades. Não percebi em nenhuma das Universidades onde estive fazendo pesquisa a preocupação de formar pessoas que saibam lidar com essa realidade de desinteresse. Não há sistematização desse conhecimento.

O filme ganhou os Kikitos de Ouro de Melhor Filme - Júri Popular, Melhor Trilha Sonora, o Prêmio Especial do Júri e o Prêmio da Crítica, no Festival de Gramado; recebeu o prêmio de Melhor Documentário - Júri Oficial, o Prêmio da Juventude e o Prêmio Bombril de Melhor Documentário Brasileiro, na Mostra de Cinema de São Paulo.

Sobre o título, Jardim explica: "é uma tentativa de dizer que Pro Dia Nascer Feliz a realidade que esse filme mostra tem que ser mudada".

\section{Nenhum a menos}

DIRETOR: ZHANG YIMOU.

ATORES: WEI MINZHI, ZHANG HUIKE, TIAN ZHENDA, GAO ENMAN, SUN ZHIMEI, LI FANFAN.

DRAMA, CHINA, 1999, 106 MINUTOS.

Um retrato da precária escola rural na China, uma história de obstinação para ganhar algum dinheiro, uma discussão sobre evasão escolar, uma lição para quem precisa dar aulas sem qualquer recurso, um exemplo do caos urbano chinês, o desenvolvimento de um processo de solidariedade. Sim, tudo isso está presente no singelo Nenhum a Menos, de Zhang Iinou.

Mas prefiro destacar aquilo que Sócrates chama de ética da consciência. A emergência de um grande compromisso com o objetivo de seu trabalho, uma responsabilidade moral, que surge e cresce numa professora, adolescente de 13 anos.

Com atores amadores e uma câmara que podemos classificar de rústica, o diretor nos apresenta muitos argumentos para uma reflexão sobre o processo pedagógico em situações-limite. E nos mostra ainda como é possível fazer um filme contundente com poucos recursos. Ele também dirigiu o poético O Caminho para Casa (ver CADERnos CenPeC, n. 2, p. 160).

A história é simples: Gao, professor de uma escola primária, precisa tirar um mês de licença para cuidar de sua mãe doente. Nada demais, se estivéssemos em um país desenvolvido. Acontece que, na pequena cidade de Shuiquan, apenas uma menina de 13 anos, Wei Minzhi, pode substituí-lo. Além disso, de uma turma de 50 alunos, apenas 28 permanecem. Nos primeiros dias de Wei, uma das alunas foi selecionada para freqüentar uma escola de esportes e um aluno de 10 anos abandona a classe para procurar emprego na cidade. $E$ o único pedido do professor Gao é o de que a classe não diminua, nem um aluno sequer. Está aí o motivo do filme: a mobilização de uma adolescente e de seus alunos, pouco mais novos, para recuperar a ovelha desgarrada, num périplo do rural para o urbano, com todos os riscos que isso pode trazer.

Num primeiro momento, o único envolvimento de Wei é com a possibilidade de ganhar uns trocados a mais, se nenhum aluno desistir. Mas isso muda. Está aí um filme que nos coloca 
diante de dilemas aparentemente insolúveis. Porém, quando se quer realmente mudar a realidade, surgem as propostas e as maneiras de implementá-las.

Nenhum a Menos ganhou o prêmio Leão de Ouro, no Festival de Veneza, em 1999.

\section{Livros e textos na Internet}

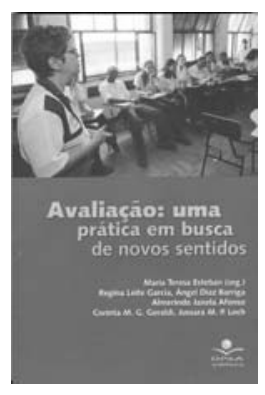

\section{Avaliação: uma prática em busca de novos sentidos}

MARIA TERESA ESTEBAN (ORG.).

REGINA LEITE GARCIA, ÁNGEL DÍAZ BARRIGA, ALMERINDO JANELA AFONSO, CORINTA M. G. GERALDI, JUSSARA M. P. LOCH. DP\&A EDITORA, RIO DE JANEIRO, RJ, 1999, 144 P.

Um pequeno livro (do último ano do século passado, que parece tão distante) desafia-nos: o que temos feito? Essa afirmação de Maria Teresa Esteban nos provoca:

O processo de avaliação do resultado escolar dos alunos e alunas está profundamente marcado pela necessidade de criação de uma nova cultura sobre avaliação, que ultrapasse os limites da técnica e incorpore em sua dinâmica a dimensão ética.

Este livro leva à reflexão, estimula a ação e, principalmente, incita a nossa indignação. No texto "Uma polêmica em relação ao exame", Angel Diaz Barriga alfineta:

O exame se converteu num instrumento no qual se deposita a esperança de melhorar a educação. (...) Um falso princípio didático: um melhor sistema de exame, melhor sistema de ensino. Nada mais falso que essa proposição. (...) a proposta técnica de fazer exames - manejo estatístico dos dados, construção de reativos, objetivos, entre outros - contribuiu ao empobrecimento da visão sobre a educação. A pedagogia do exame criou mais problemas para a educação do que resolveu.

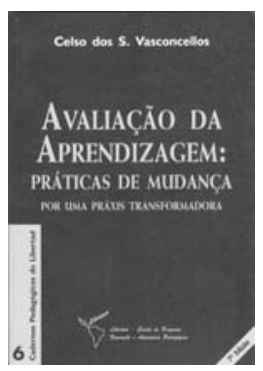

\section{Avaliação da aprendizagem: práticas de mudança. Por uma práxis transformadora.}

CELSO DOS S. VASCONCELLOS. EDITORA LIBERTAD, COLEÇÃO CADERNOS PEDAGÓGICOS, SÃO PAULO, SP, 2005, 7ㄹ EDIÇÃO, 232 P.

Celso Vasconcelos se propõe a responder perguntas que vivem sem resposta nas mentes de milhares de pessoas:

- Como passar das muitas análises do papel político da avaliação, das simples negações das práticas avaliativas dos professores, do uso de uma linha avaliativa ingênua ou reprodutora para a construção de caminhos concretos na perspectiva crítica?

- O que fazer a fim de superar as práticas autoritárias de avaliação ou, ao menos, o que fazer em termos de preparação para uma mudança maior?

- Como avançar para além do discurso e traduzir em ações a nova visão da avaliação?

Aqui, o leitor encontrará boas respostas, e explicações para elas ainda não terem sido utilizadas. Mas Vasconcelos não desanima, muito menos os leitores, já que o livro está na sétima edição. Para ele:

(...) o ser humano gosta de desafios (...); a tarefa que está posta é superar sua formulação alienada - "ser o melhor", "conseguir nota", "passar de ano" - e apontar novas tarefas para os alunos: aprender mais e melhor; não deixar ninguém pelo caminho, avançar juntos ("nenhum a menos"); refletir, desfrutar o prazer de conhecer; pensar com a própria cabeça; descobrir novas possibilidades de organização do real; ser capaz de intervir, abrir novos horizontes dentro e fora da escola.

Na perspectiva de uma práxis transformadora, Vasconcelos defende que a avaliação deve ser considerada um compromisso com a aprendizagem de todos e com a mudança institucional. 


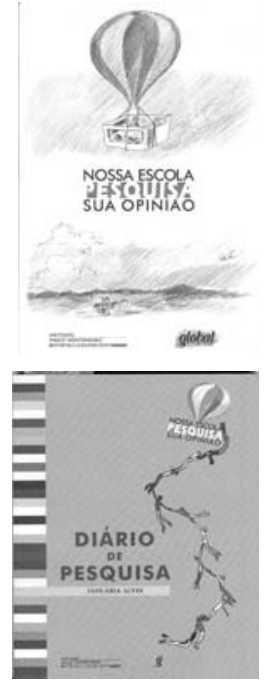

\section{Nossa escola pesquisa sua opinião}

MANUAL DO PROFESSOR. INSTITUTO PAULO MONTENEGRO / GLOBAL EDITORA, SÃO PAULO, 2002, 2ª EDIÇÃO, 192 P.

\section{Nossa escola pesquisa sua opinião}

DIÁRIO DE PESQUISA

JANUÁRIA ALVES.

INSTITUTO PAULO MONTENEGRO / GLOBAL EDITORA, SÃO PAULO, SP, 2002, 2a EDIÇÃO, 192 P.

0 aluno é sempre avaliado. Em tese, na teoria e na prática, é ele quem precisa "passar de ano". Mas... e os professores, e os gestores, e a escola, e os pais, e a comunidade? Os resultados das avaliações da educação brasileira não têm sido muito animadores. Quem sabe, se pudéssemos fazer uma avaliação "em processo" da educação - conhecer melhor alunos, professores, gestores, condições materiais da escola, pais, comunidade, durante 0 período letivo - conseguíssemos melhores resultados? É exatamente isso o que propõem estes dois livros, editados pelo Instituto Paulo Montenegro, uma ONG voltada para a educação, do Instituto Brasileiro de Opinião Pública e Estatística, mais conhecido como Ibope. Logo no início, o livro propõe:

Você já parou para pensar por que fazemos pesquisa de opinião? Por que a opinião sobre outras pessoas e fatos é tão importante que precisa ser medida? Responda, então, ao teste:

Fazemos pesquisa de opinião:

a. Para averiguar a existência de algum problema?

b. Para confirmar a continuidade de uma ação que já está em andamento?

c. Para compreender a visão que as pessoas têm de um fato ou de alguma ação em curso?

d. Para detectar a dimensão de algum problema ou de alguma ação?

e. Para refletir sobre como agir, como mudar, como superar, ou como reafirmar as posições ou caminhos já escolhidos?

f. Todas as alternativas anteriores estão corretas.

É claro que você optou pela alternativa "f”. Estes dois livros ensinam tudo isso. Resta saber se todos os envolvidos estão dispostos a serem avaliados. Mas que vale a pena não apenas ler os livros como também colocar suas idéias em prática, lá isso vale! E ainda há um ótimo sítio para se esclarecerem as dúvidas: 〈www.ipm.org.br〉.

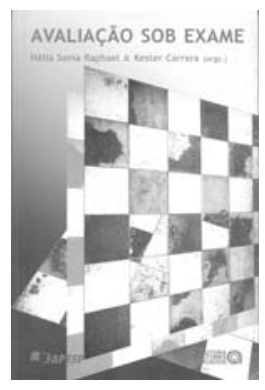

\section{Avaliação sob exame}

HÉLIA SONIA RAPHAEL E KESTER CARRARA (ORG.).

ALDA JUNQUEIRA MARIN (COM: CLAUDIA CRISTINI FLORIO GUILHERME, JOSELY KOBAL DE OLIVEIRA, MARIA CRISTINA DE SENZI ZANCUL, MARIA IOLANDA MONTEIRO), ANA CLÁUDIA BARTOLOZZI MAIA, ELIANA MARIA GRADIM FABRON, LÉA DEPRESBITERIS, MIGUEL CLÁUDIO MORIEL CHACON, RITA DE CÁSSIA TIBÉRIO ARAÚJO, ROSALY MARA SENAPESCHI GARITA, SADAO OMOTE.

FAPESP / EDITORA AUTORES ASSOCIADOS, CAMPINAS, SP, 2002, 226 P.

Pedagogia e psicologia sempre andaram juntas. A psicologia é um dos principais instrumentos de inteligência do processo pedagógico. E isso faz sentido: a pedagogia tem sido prioritariamente chamada a se relacionar com crianças e jovens, para desenvolver processos 
de aprendizagem; e para se conhecer essa população, a psicologia é imprescindivel. As autoras, contudo, chamam a atenção para a abrangência da questão pedagógica e remetem os leitores para questões mais amplas. Elas mesmas advertem:

O que se torna necessário é o entendimento das questões emanadas da psicologia da educação, da sociologia, da filosofia, da antropologia e de quaisquer outras áreas do saber presentes na questão abordada, como algo indissociável, ou seja, uma totalidade de inter-relações que oferecem um entendimento dinâmico do processo avaliatório.

É nessa direção que caminham os oito estudos apresentados, que tratam desde as óticas teóricas e processo de construção da cidadania - ao propor uma avaliação da avaliação, e avaliação diagnóstica em educação especial - até a abordagem ecológica na análise de notas escolares, além da pergunta crucial: podemos ser conscientes quando avaliamos?

\section{Leia mais}

Para quem deseja mais informações, indicamos também outros livros e artigos.

\section{Livros}

Análise das práticas dos professores e das situações pedagógicas

MARGUERITE ALTET. PORTO EDITORA, PORTO, PORTUGAL, 2000, 192 P.

\section{Avaliação educacional: regulação e emancipação}

ALMERINDO JANELA AFONSO. CORTEZ EDITORA, SÃO PAULO, SP, 2000, 2ํㅡㄹㄷÃO, 152 P.

\section{Escola, currículo e avaliação}

MARIA TERESA ESTEBAN (ORG.). ALMERINDO JANELA AFONSO; ANA LÚCIA SOUZA DE FREITAS; MAILSA CARLA PASSOS E CARLOS ROBERTO DE CARVALHO; ANELICE RIBETTO, GENI AMÉLIA NADER VASCONCELOS, PAULO SGARBI E VALATER FILÉ; INÊS BARBOSA DE OLIVEIRA E DIRCEU CASTILHO PACHECO; MARIA CLÁUDIA REIS FERRAZ E STELLA MARIS MOURA DE MACEDO; CARMEN SANCHES SAMPAIO. CORTEZ EDITORA, SÉRIE: CULTURA, MEMÓRIA E CURRÍCULO, SÃO PAULO, SP, 2003, 168 P.

\section{Mitologias da avaliação - de como ignorar, em vez de enfrentar problemas} PEDRO DEMO. EDITORA AUTORES ASSOCIADOS, COLEÇÃO: POLÊMICAS DO NOSSO TEMPO, CAMPINAS, SP, 2002, 86 P.

\section{Artigos na Internet}

\section{A avaliação do desempenho escolar como ferramenta de exclusão social}

ANDRÉA CRISTINA MARQUES DE ARAÚJO

Disponível em: 〈http://www.ccuec.unicamp.br/revista/infotec/artigos/andrea_cristina2.html.〉

\section{A dimensão reflexiva da avaliação}

ENTREVISTA COM MARIA TEREZA ESTEBAN

Disponível em: 〈http://www.tvebrasil.com.br/salto/entrevistas/maria_teresa_esteban\%20.htm〉. 


\section{Avaliação educacional e projeto político-pedagógico}

MOACIR GADOTII.

Disponível em: 〈http://www.paulofreire.org/Moacir_Gadotti/Artigos/Portugues/Curriculo/Avali_educacional_PPP.pdf).

\section{Avaliação na pedagogia de projetos PGM 5 - Práticas avaliativas na pedagogia de projetos} MARIA TERESA ESTEBAN

Disponivel em: 〈http://www.tvebrasil.com.br/SALTO/boletins2002/aas/aastxt5.htm〉.

\section{Avaliação: uma roupa nova em um corpo novo}

FLORA SUMIE TAKAMORI, LUIZ SEABRA JÚNIOR, MARIA LOURDES VIEIRA

Disponível em: 〈http://www.unipinhal.edu.br/movimentopercepcao/include/getdoc. php?id=58\&ticlem28odeffi.

\section{Avaliar para crescer}

REPORTAGEM: PAOLA GENTILE

Disponível em: 〈http://novaescola.abril.uol.com.br/index.htm?ed/138_dezoo/html/avaliacao〉.

\section{Boa gestão, e não orçamento maior, determina boas notas.}

\section{SIMONE IWASSO}

Disponível em: 〈http://www.estado.com.br/editorias/2007/03/25/ger1.93.7.20070325.8.1.xml».

\section{Educação infantil inspira avaliação formativa}

ENTREVISTA: ANTONI ZABALA

Disponível em: 〈http://novaescola.abril.uol.com.br/ed/138_dezoo/html/zabala.doc〉.

\section{Intencionalidade: palavra-chave da avaliação}

ENTREVISTA: CELSO DOS SANTOS VASCONCELOS

Disponível em: 〈http://novaescola.abril.uol.com.br/ed/138_dezoo/html/celso.doc〉.

\section{Sítios}

\section{www.abave.org.br}

INTERCÂMBIO DE EXPERIÊNCIAS

A Associação Brasileira de Avaliação Educacional - Abave é uma associação de natureza científica que se apresenta como um espaço de intercâmbio de experiências entre os acadêmicos e os implementadores da avaliação educacional.

\section{http://www.inep.gov.br/}

\section{AVALIAÇÃO INTERNACIONAL}

Entre no site do INEP - Instituto Nacional de Estudos e Pesquisas Educacionais Anísio Teixeira. No menu, do lado esquerdo, encontra-se a área Biblioteca Virtual de Educação. Ela traz uma relação de sites internacionais com textos sobre avaliação.

\section{http://www.unesco.org.br/}

EDUCAÇÃO NO BRASIL E NO MUNDO

Unesco-Organização das Nações Unidas para a Educação, a Ciência e a Cultura - sítio no qual se pode conhecer a atuação da entidade no mundo em suas diversas áreas de atu- 
ação: Educação, Ciências Naturais, Ciências Humanas e Sociais, Cultura, Comunicação e Informação, Pesquisa e Avaliação.

\section{http://www.preal.org/Default.asp}

PRÁTICAS EDUCACIONAIS LATINO-AMERICANAS

PREAL - Programa de Promoção da Reforma Educativa da América Latina e Caribe promove a participação de diversos atores sociais no desenvolvimento e aperfeiçoamento de políticas, além de estimular a busca de acordos nacionais para melhorar a qualidade, eqüidade e eficácia dos sistemas educativos na região.

\section{www.ice.deusto.es/rinace/}

PESQUISA SOBRE QUALIDADE E EQÜIDADE

A Rede Ibero-Americana de Investigación sobre Cambio e Eficacia Escolar é uma rede de pesquisadores em educação comprometidos em aumentar os níveis de qualidade e eqüidade dos sistemas educativos.

\section{www.icsei.net.}

\section{EFEITO ESCOLA}

Um grupo de pesquisadores de todo o mundo tem realizado conferências anuais sobre o tema da Escola Efetiva - International Congress for School Effectiveness and Improvement - oferecendo contribuições importantes para o desenvolvimento da pesquisa sobre os efeitos da escola. Em inglês.

\section{www.ncrel.org}

DESENVOLVIMENTO PROFISSIONAL E PESQUISA

Para leitores de língua inglesa, o sítio do Learning Point Associates oferece pesquisas, recursos de desenvolvimento profissional para professores e informa sobre as melhores práticas existentes para o aperfeiçoamento da eficácia escolar. 


\section{Cadernos Cenpec}

ANO II

NÚMERO 3

PRIMEIRO SEMESTRE DE 2007

Cadernos Cenpec é uma publicação do

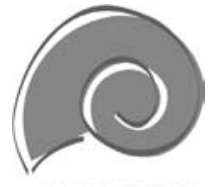

CENPEC

Cenpec - Centro de Estudos e Pesquisas em Educação, Cultura e Ação Comunitária

Rua Dante Carraro, 68

05422-060 - São Paulo - SP

Brasil

Telefax: (55) (11) 21329000

cenpec@cenpec.org.br

www.cenpec.org.br

Os artigos assinados não representam necessariamente os ponto de vista do CENPEC. As opiniões e idéias expressas neles são de responsabilidade exclusiva de seus autores.

\section{Cenpec}

Centro de Estudos e Pesquisas em Educação, Cultura e Ação Comunitária

\section{PRESIDÊNCIA}

Maria Alice Setubal Diretora Presidente

Ricardo Campus CaIUby ARIani Diretor Vice-Presidente

Diretores Administrativos

Lydia Maria Queiroz Ferreira de Magalhães

Tereza Maria Macedo Soares de Araújo

Conselho de Administração

antonio Carlos Caruso Ronca

BERNARDETE ANGELINA GATTI

HÉLIO MATTAR

Maria Alice Setubal

Michel Paul ZeitLin

Ricardo Campos CaIUby Ariani

Conselho Fiscal

Reginaldo José CAMILO

Rebecca de Castro Filgueiras Raposo

CoORdenação

Coordenadora Geral

maria do Carmo Brant de Carvalho

Assessoria da Coordenação

MARIA Ângela LEAL RUdge

MARIA CRISTINA S. ZelmanovitS

Carola Carbajal Arregui

Coordenadora Administrativo-Financeira

MARIA APARECIDA ACUNZO ForLI 


\author{
Créditos desta edição \\ Organização e Coordenação \\ ISA MARIA F. ROSA GUARÁ \\ Comitê Editorial \\ Ana Regina Carrara \\ ELOÍSA DE BLASIS \\ FERNANDO RIOS \\ ISA MARIA F. ROSA GUARÁ \\ Maria do Carmo Brant de Carvalho \\ Conselho Editorial \\ ÂMBAR DE BARROS \\ Antonio Jacinto Mathias \\ BERNADETE GATTI \\ FERnANDo Almeida \\ FERNANDO ROSSETTI \\ GILDA PORTUGAL GOUVEIA \\ ISA MARIA F. ROSA GUARÁ \\ Marco Aurélio Nogueira \\ Maria Alice Setubal \\ Maria do Carmo Brant de Carvalho \\ VERA MASAgÃo
}

Colaboram nesta edição

Ana luíza Mendes Borges

Ana Maria Falsarella

BERNARDETE GATTI

Claudia Petri

DENISE BLANES

ERIKA HIMMEL KÖNIG

GABRIEL GROSSI

HELoÍSA TRENCHE

JoANA BUARQUE DE GUSMÃO

JORGE KAYANO

José FRANCISCO SOARES

JOSÉ HAMILTON MARUXO JÚNIOR

LILIANE PETRIS

MÁrCIA PADILHA Lotito

MARIA AMÁBILE MANSUTTI

MARIA DE SALETE SiLVA

Maria Helena Guimarães de Castro

Mílada Tonarelli Gonçalves

NaÉrcio MEnezes
Priscila Gonsales

REgINA SCARPA

SÔNIA MARIA DE OLIVEIRA NUdELLMAN

TÂNIA REgINA DE SOUZA RoMERo

TEREZINHA AZERÊDO RIOS

VAnda Mendes Ribeiro

VAnda Noventa Fonseca

Vera Masagão Ribeiro

WALDENIR (NINO) BERNINI LICTENTHALER

Redator

FERNANDO RIOS

Revisão e preparação de textos

Dora Helena Feres

SYLMARA BELETTI

Projeto gráfico original

homem de Melo \& Troia Design

Diagramação e editoração eletrônica

FONTE DESIGN

Fotos

JoÃo KULCSÁR (consultor)

Arquivo Prêmio Cultura Viva

ARQUIVO UNICEF

DANIEL MALVA

Daniela Savastano

FERNANDO RIOS

Tiragem

2.000 exemplares

Cadernos Cenpec / Centro de Estudos e Pesquisas

em Educação, Cultura e Ação

Comunitária. - N. 3 (2007) -

São Paulo: CENPEC, 2007

ISSN 1808-9631

Semestral

1. Educação 3. CENPEC

CDD 370 


\section{cadernoscenpec \\ ADERNOS CENPEC:

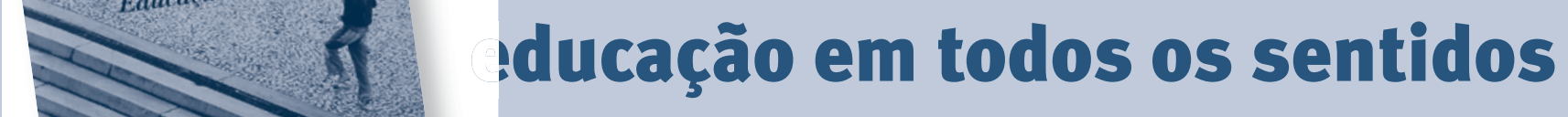

CADERNOS CENPEC é um importante periódico brasileiro dedicado à discussão dos grandes problemas da educação pública brasileira e sua interface com a cultura e as ações sociais. Os dois primeiros números abordam temas que estão na pauta das questões educacionais e deverão continuar por muito tempo: Cidade Educadora e Educação Integral. Este terceiro volume trata de Avaliação em Educação.

Em cada edição, o Cenpec utiliza sua larga experiência, por meio de artigos de seus colaboradores diretos, e convida especialistas para desenvolverem temas específicos. CADERNOS CENPEC é dirigido a professores, gestores escolares, administradores e políticos, enfim, a todos aqueles comprometidos com a melhoria da educação brasileira.

o Cenpec é uma das principais organizações não-governamentais brasileiras que atua na formação e aperfeiçoamento técnico-pedagógico das equipes de educação, cultura e ação social e no desenvolvimento de projetos, metodologias e recursos didáticos voltados para a educação integral.

\section{Em cada revista, um tema atual.}

No volume 1, que trata de Cidade Educadora, um grupo de renomados educadores debate o tema "Qual cidade educadora queremos". Outros artigos abordam a educação na cidade sob diferentes olhares, as possibilidades de organização de uma cidade voltada para a educação, a utilização dos espaços educativos, práticas e experiências de educação articuladas com a comunidade, além de indicações e propostas para uma boa política municipal de educação.

No volume 2, que discute Educação Integral, os artigos abordam experiências que vão do campo à cidade na busca de um lugar da educação integral na política social. Discutimos o que se diz sobre a escola pública de horário integral e as possibilidades educativas de diversos espaços complementares compondo, com a escola, um programa de tempo integral. Refletindo sobre os conceitos de cidadania integral, escola de tempo integral e educação integral, a edição apresenta relatos e depoimentos que ilustram os caminhos teóricos.

\section{Contribuição teórica e prática}

"Educação parece ser o grande desafio da sociedade brasileira", comenta a professora Maria do Carmo Brant de CarvaIho, coordenadora geral do CENPEC, que argumenta: "não estamos conseguindo preparar corretamente os alunos das escolas públicas para enfrentar uma sociedade altamente competitiva, que veicula uma grande quantidade de informação e que exige uma consistente formação profissional. Com esta publicação, queremos contribuir, teórica e praticamente para discutir, entre outros temas, a formação e o papel dos professores na sociedade do conhecimento, a relação entre violência e conhecimento na escola, a importância dos gestores escolares e a formulação e implementação de políticas públicas em educação".

\section{Como adquirir}

CADERNOS CENPEC podem ser comprados diretamente na instituição.

Para adquirir a publicação, você também pode acessar o site: 〈www.cenpec.org.br > e seguir as instruções de compra.

O preço é $R \$ 20,00$, por exemplar. Quantidades acima de 20 exemplares têm desconto de $20 \%$.

Mais informações pelo telefone 112132.9000 ou pelo email 〈revista@cenpec.org.br >

Os CADERNOS estão à venda também na Livraria Cortez. Telefax 11 3873.7111; site: 〈www.livrariacortez.com.br 〉

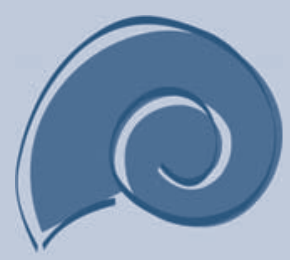

\section{CENPEC}

Cenpec - Centro de Estudos e Pesquisas

em Educação, Cultura e Ação Comunitária

Rua Dante Carraro, 68, 05422-060

Pinheiros, São Paulo, SP.

Telefone: 55112132.9000

E-mail: cenpec@cenpec.org.br

Site: www.cenpec.org.br 


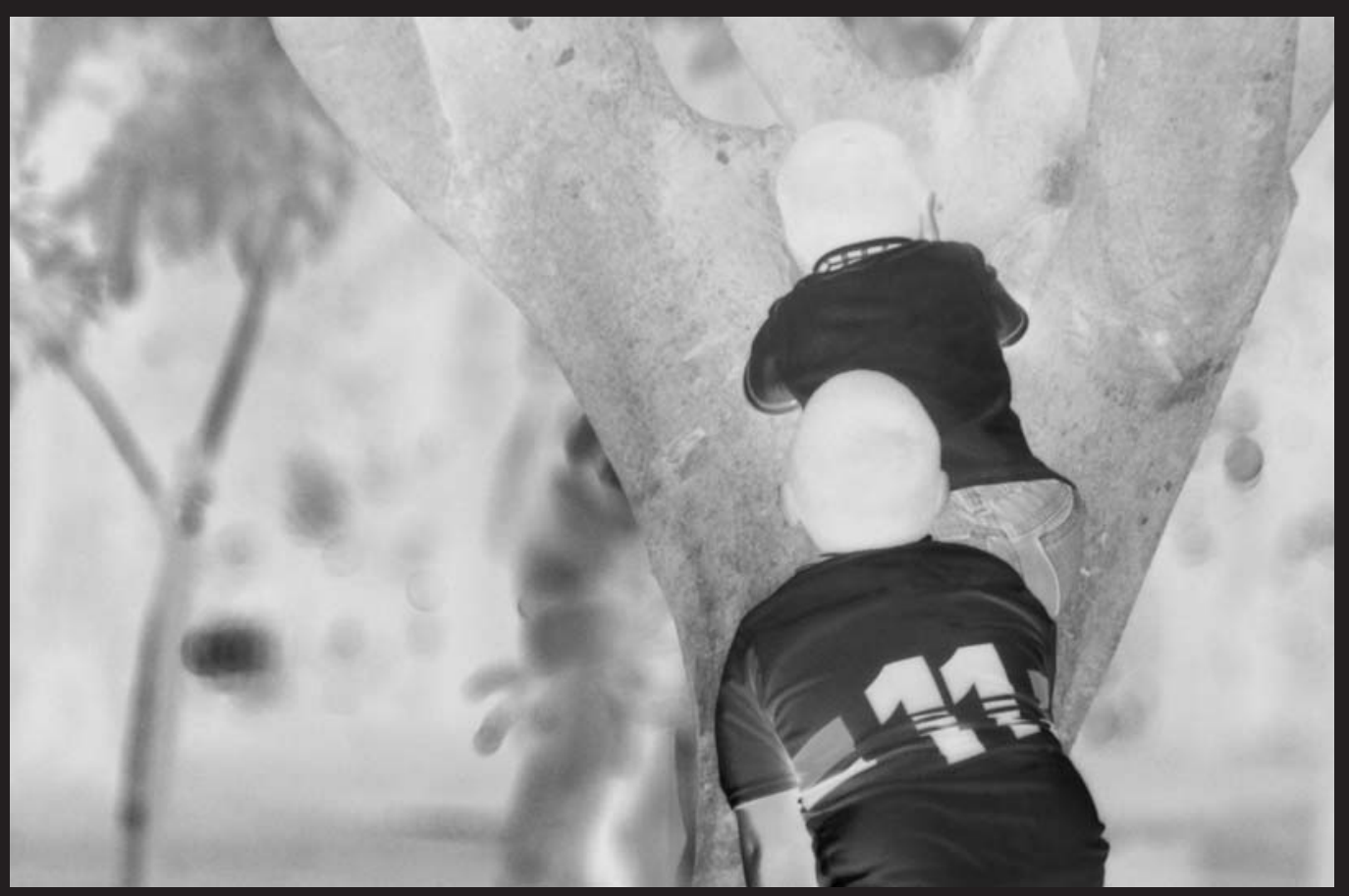

